\title{
CONGENITAL NARROWING OF THE SPINAL CANAL
}

\author{
By D. O. HaNCock, F.R.C.S. \\ Neurosurgical Department, Morriston Hospital, Swansea
}

THE account of a congenitally narrowed spinal canal is gaining general acceptance. Verbiest first drew attention to the condition in the lumbar region in 1954, and subsequently a number of papers has appeared in support (Verbiest, I955; Epstein et al., I962; Teng \& Papatheodorou, I963; Graveleau \& Guiot, I964; Ehni, I965; Joffe et al., I966). Ehni believes that the condition has been described without full realisation of the underlying abnormality, and quotes the papers of Bailey and Casamajor (I9II), Cramer (I934), and Blau and Logue (I96I), among others. He also adds that significant narrowing occurs in the cervical spinal canal, causing the symptoms in some instances of cervical spondylosis. Payne and Spillane (1957) found the sagittal diameter of the cervical canal below normal in patients with spondylosis, and especially so if paraplegia were present. Recently Hinck et al. (1964, I966) have reported six patients with severe narrowing in the cervical spine.

If the spinal cord or cauda equina is contained within a canal of more limited dimensions than normal, clearly, intrusions by intervertebral discs and bony spurs produce symptoms more readily. The effects in the lumbar region give rise to symptoms in the lower limbs; in the neck, all limbs may be involved. Bizarre symptoms may occur in the lumbar variety-Van Gelderen (1948) cites two patients who had symptoms on standing, kneeling and walking; however, one could ride a bicycle and the other play tennis without symptoms! One of Graveleau and Guiot's (1964) patients lost the awareness of his lower limbs when he walked. Ehni (1965) points out that neurological damage, even causing paraplegia, may follow operations in the supine position under spinal or general anaesthesia. Patients find that symptoms are relieved by spinal flexion, in which position the antero-posterior diameter of the spinal canal is at its maximum. Neurogenic intermittent claudication (Dejerine, I9I I; Blau \& Logue, I96I; Evans, 1964) is commonly present when there is a narrow lumbar canal. In the acute phase symptoms and signs resemble those of acute sciatica, but in the chronic variety signs may be few and the Lasêgue test often negative (Epstein, I960).

Teng and Papatheodorou (1963) describe the salient radiographic features in the lumbar region-plain films detect osteophytic lipping and hypertrophic interspinal joints. The myelogram shows intrusions from both behind and in front of the theca, often at several intervertebral levels. Constriction is most common at the lumbar fourth/fifth level, next at third/fourth, and then second/third.

Dr J. L. G. Thomson of Bristol (personal communication) has suggested that if the ratio of the areas of the spinal canal to the lumbar vertebral bodies is measured, canal narrowing may be detected. This eliminates errors due to distortion, magnification and the size of the patient. In a series of fifty normal patients he found it to vary between $I: 2$ and $I: 4 \cdot 5$. A ratio greater than $I: 5$ suggests abnormal narrowing. 
Epstein et al. (I962) have described the anatomical configuration of the affected vertebrae. The interspinal articulations are vertically orientated, and the hypertrophic interspinal joints abut on the spinous processes. Lumbar puncture (L.P.) may be impossible because the thickened laminae overlap. The lateral limits of the canal are extraordinarily narrow, and particular care needs to be taken to unroof this aspect at laminectomy.

Of the symptoms in the cervical region, impairment of cord function is usually more evident than brachial radiculitis. Limb weakness is usually complained of, together with digital numbness. A history of a hyperextension injury precipitating these symptoms is common. On examination spastic weakness involving all four limbs is usually found, giving rise to a spastic gait; fasciculation may be noted in the upper limb muscles, and occasionally sensory impairment.

Radiologically, the sagittal diameter of the cervical canal is below normal (Hinck et al., 1962, 1966), and osteophytes are present. Myelography reveals either complete or partial block; in the latter, neck flexion allows the oil to flow onwards. As in the lumbar region posterior and anterior intrusions form a point in the Myodil shadow (Fig. 7).

In both cervical and lumbar regions the age incidence varies between the third and eighth decades, and occurs maximally at the fifth.

\section{Case Reports}

E. B., male aged 39. He first complained of low central backache at the age of $2 \mathrm{I}$. This continued intermittently for a further thirteen years, when symptoms reminiscent of intermittent claudication were added. Pain radiated posteriorly down both lower limbs on walking, and relief was rapidly obtained by bending forwards. If he attempted to micturate while in pain, the stream was poor. When he bent forwards to relieve the pain, the stream improved! He was impotent. Abnormal clinical signs consisted only of an absent right ankle jerk and diminution of vibration sense at both ankles. L.P. was impossible. Plain X-rays (Fig. I) show an oblique orientation of the interspinal joints. The interpedicular distance at the third lumbar level was 30 millimetres $(\mathrm{mm}$.$) , at the$ fourth $28 \mathrm{~mm}$., and at the fifth $27 \mathrm{~mm}$.- the reverse of normal (Elsberg and Dyke, 1934). Initially cisternal myelography located a complete block at the lower border of the third lumbar vertebra (Fig. 2). A later myelogram showed that the greater part of the Myodil had seeped past the obstruction, but that pockets remained behind the vertebral bodies (Fig. 3).

Laminectomy was difficult because the laminae overlapped each other very closely. The dura bulged outwards as bone was excised; no extradural fat was seen between the lower border of the fifth and the lower border of the third lumbar vertebrae. The cauda equina appeared normal when the dura was opened. Eleven months later he was completely relieved of the claudication, though still impotent. Vibration sense had returned, but the right ankle jerk was still absent.

Comment. This is a classic example of congenital canal narrowing, with abnormal diminution of the interpedicular distances in the two lowest vertebrae. His history is characteristically bizarre, and the diagnosis is also suggested by the presence of intermittent claudication. Laminectomy relieved the majority of the symptoms.

E. D., male aged 5I. This patient had a four-year history of intermittent right-sided sciatica when admitted to the Morriston Hospital in 1953. An absent ankle jerk was found on that side, with sensory loss over the first sacral dermatome. At operation (fifth lumbar laminectomy) the nerve root was found to be trapped 'between a sessile 
protrusion and the overlying articular facet'. This overlying bone was excised-the disc was not.

In 1959 he presented with weakness of the right upper limb and was found to have some wasting of the triceps. There was no sensory loss and cervical spine $\mathrm{X}$-rays were reported to be normal. He received a course of faradism and some improvement was obtained.

He re-appeared in 1966 with a six-months' history of difficulty in walking and an

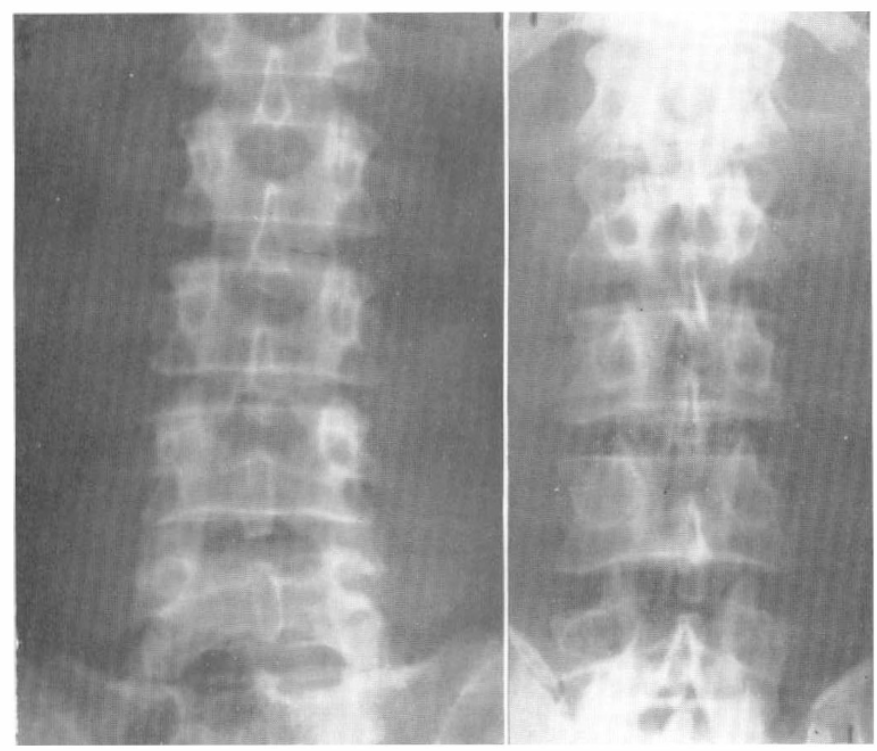

FIG. I

Normal lumbar spine on left, E.B.'s on right. The narrowed canal is evident, together with the malalignment of the thickened interspinal joints. The ratios (see text) are: L2, I:5; $\mathrm{L}_{3}, \mathrm{I}: 4 \cdot 5 ; \mathrm{L} 4, \mathrm{I}: 5 ; \mathrm{L} 5, \mathrm{I}: 4 \cdot 5$.

uncontrollable shaking of the left leg. There was a six-week history of pain radiating down the outer aspect of both forearms to the little fingers. There was no sphincteric disturbance. Examination showed wasting and weakness of the right triceps, biceps and brachio-radialis. There was no fasciculation. Triceps and supinator reflexes were absent on this side and the biceps reflex was depressed. The left upper limb was normal. The right abdominal reflexes were absent. In the lower limbs, straight leg raising was unrestricted, the knee jerks very brisk but not clonic. The right ankle jerk could just be elicited, the left one was brisk and clonic. The left plantar response was flexor, the right extensor. Position sense was normal throughout, and vibration sense impaired up to the knees; there was a glove and stocking hypoalgesia. The gait was spastic. L.P. was normal, there were no cells in the cerebro-spinal fluid (C.S.F.) and the protein content was 45 milligrams per cent. (mg. per cent.). Plain X-rays of the neck showed narrowing of the sagittal diameter of the spinal canal, and the disc space between the fifth and sixth vertebrae was narrowed, with osteophyte formation also (Fig. 4). Myelography demonstrated a complete block at this level which could not be overcome by flexing the neck (Fig. 5). 
At operation the laminae were removed from the second to the seventh cervical level inclusively, the third to sixth being extraordinarily thin. Post-operative screening showed no obstruction to the flow of Myodil in the neck, although there were several protruding intervertebral discs. When the patient was seen six months later improvement was continuing. The left leg shook somewhat only when he lay down, but walking

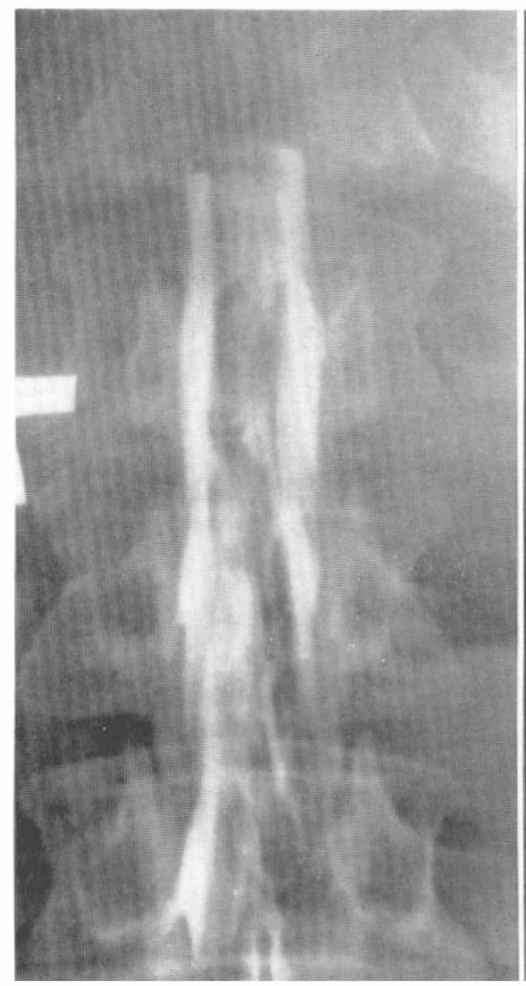

FIG. 2

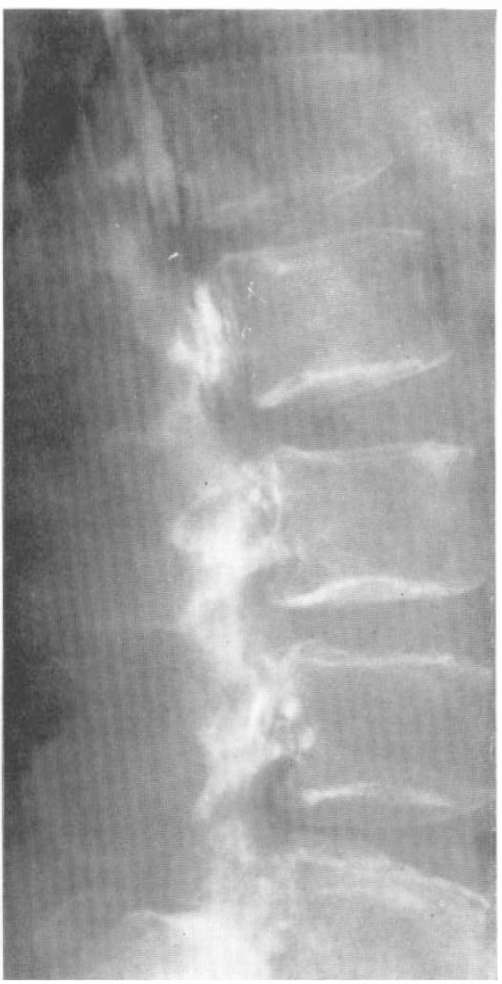

FIG. 3

Figure 2-Initial myelogram. Complete hold up at L3; appearances suggest an arachnoiditis.

Figure 3-Later myelogram. 'Pocketing' is seen behind each body. Note the size of the spinous processes.

was easier. The right abdominal reflexes had returned, and the right ankle jerk was normal, the left no longer clonic, and both plantar responses flexor. The gait showed only a mild foot drop on the left. The upper limbs were unaltered in power and reflexes.

Comment. The findings at the operation in 1953 are suggestive of a narrowed spinal canal at the fifth lumbar level (myelography was not performed). The myelogram performed in 1966 showed only a minor disc protrusion at the interspace between the fourth and fifth lumbar vertebrae. The cervical laminectomy 'uncovered' a number of protruding cervical discs-none the less improvement was achieved. It seems possible that this patient's spinal canal was narrowed in both the lumbar and cervical regions. 


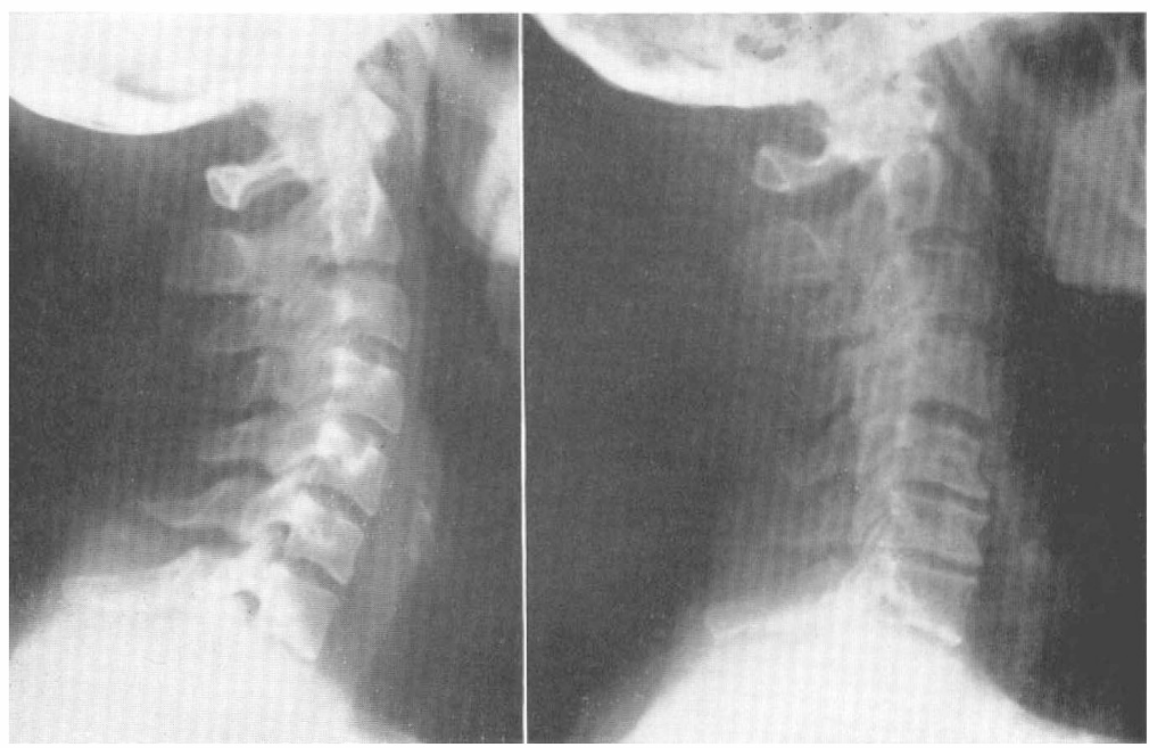

Fig. 4

Normal cervical spine on left, E.D.'s on right. The funnel shape of the canal is evident.

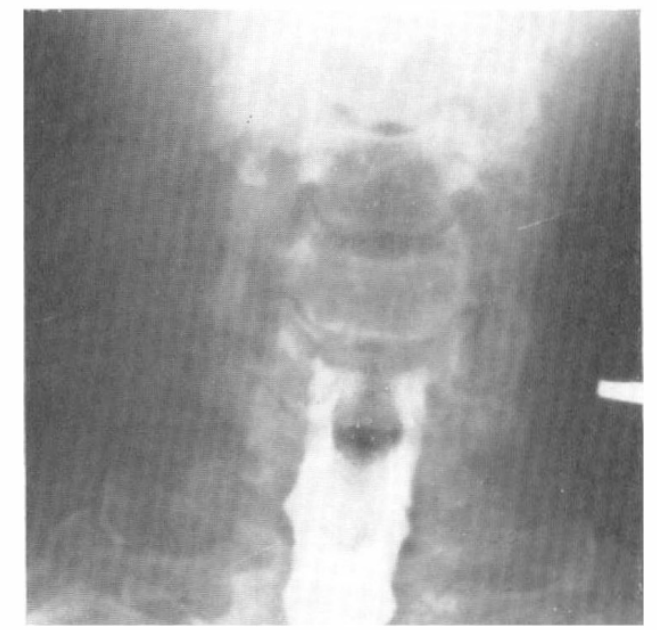

FIG. 5

Complete block on myelography at the upper border of C6.

D. E. W., male aged 58. He had noticed a progressive weakness of the right leg for two years. There was no accompanying pain. Latterly the rate of progression of the weakness had increased, and he was dragging his right foot. Accompanying this recent worsening in power was a sensation of pins and needles in both feet and fingers, with 
loss of dexterity. There was also urgency of micturition, but no incontinence. Examination revealed wasting and weakness of the right biceps and triceps muscles, but no fasciculation. The upper limb reflexes were normal, and the abdominal reflexes present. The lower limbs were spastic, the knee jerks increased but not clonic, and the ankle jerks normal; the right plantar response was extensor, and the left flexor. There was impairment of pin-prick sensation up to the fourth dorsal dermatome and a glove

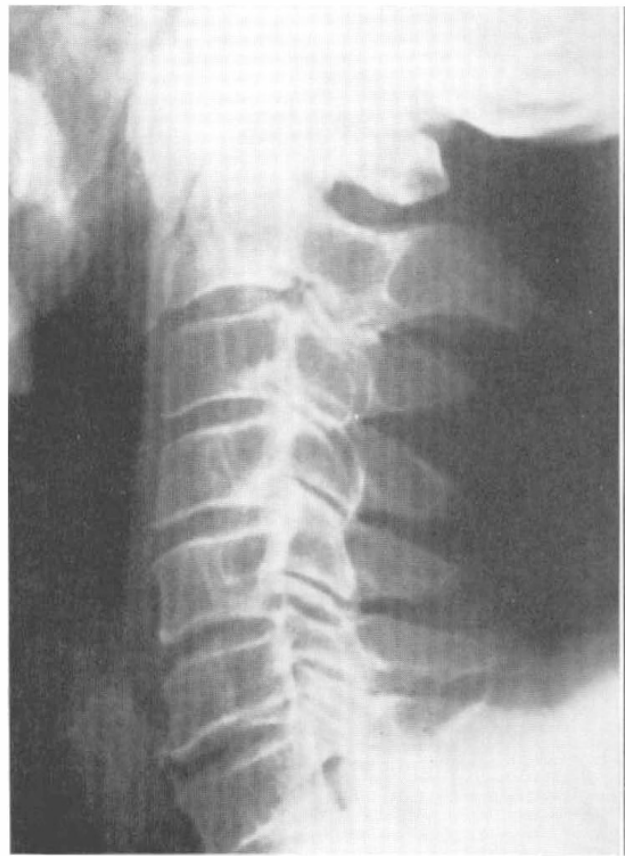

FIG. 6

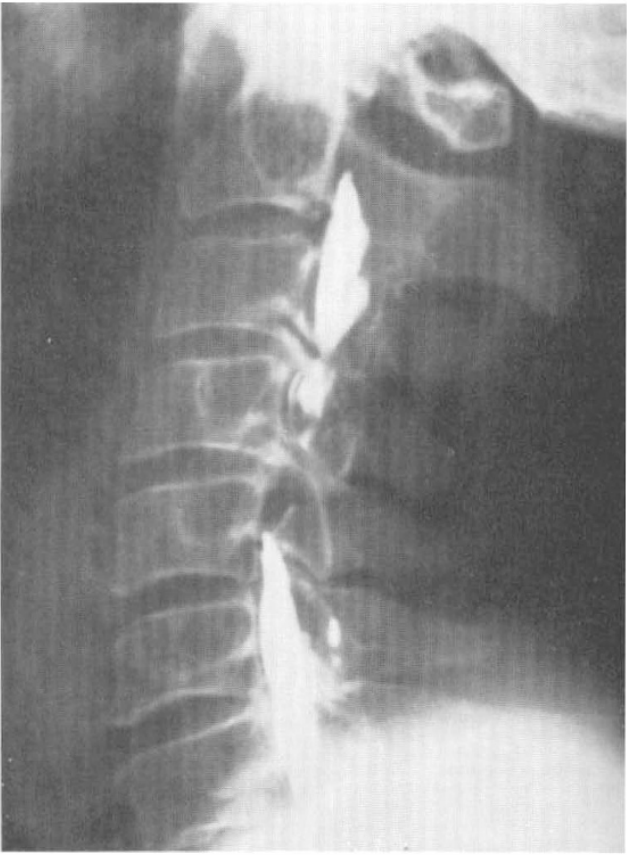

FIG. 7

Figure 6-Localised narrowing at $\mathrm{C}_{3}, 4,5$ (D.E.W.).

Figure 7-Note the 'arrow's head' appearance of the upper bolus of Myodil, indicating the presence of anterior and posterior intrusions.

hypoalgesia on both sides; position and temperature sense were intact throughout, but vibration sense was lost at the ankles. The gait was spastic with 'scissoring'. L.P. was normal, and the C.S.F. contained $45 \mathrm{mg}$. per cent. of protein, one lymphocyte and 35 red blood cells. Plain X-rays of the neck (Fig. 6) showed narrowing of the sagittal diameter at the third, fourth and fifth vertebral levels. There was a small posterior disc protrusion between the fourth and fifth vertebrae; myelography showed an almost complete obstruction at this level. Some Myodil was manoeuvred past on extreme lateral flexion only. The oil was held up in its downward passage at the space between the third and fourth vertebrae and there were anterior and posterior indentations here (Fig. 7).

At operation the third to seventh laminae were removed, the dura bulging through the first bone cuts. These laminae were normal in thickness. Rescreening afterwards showed a rapid flow of dye through the cervical canal. Two months later the patient's walking was improved, but he suffered a burning ache in the right hip and knee. Pins and needles remained only in the fingers, and was improving. Examination showed normal power in the upper limbs despite the unaltered wasting; the reflexes were also 
unaltered. The lower limb reflexes were also unchanged, though both plantar responses were now extensor. The glove hypoalgesia persisted, but the upper sensory level had dropped a segment. Vibration sense was now normal throughout and scissoring of the gait no longer apparent.

Comment. He is quite similar to E. D.; both showed a spastic weakness in the lower limbs and wasting in the upper ones. It is very likely that the wasting recorded in E. D.'s right upper limb in 1959 was due to his stenotic cervical canal; he was aware of lower limb weakness only six months before his operation, whereas D. E. W. had noticed it for two years. Hinck et al. (1964, 1966) found wasting of the more proximal upper limb musculature in one of their patients whose relevant history may well have extended over eight years. It is possible that the presence of wasting of the proximal upper limb muscles in this condition is a manifestation of chronicity. In all three cases laminectomy resulted in improvement, most notably of the gait.

\section{DISCUSSION}

Evidence is growing to show that narrowing of the spinal canal occurs in both the lumbar and cervical regions. It is likely that neurological abnormalities arise because the canal is developmentally narrowed, and that changes in the spine associated with ageing and normally tolerated, cause symptoms and signs in a patient thus predisposed.

The dural tube is tightly incarcerated, myelography showing that communication along the subarachnoid pathway is either severely attenuated or obstructed. There is therefore abnormal compression of the spinal cord and/or nerve roots. It has been suggested that neurogenic intermittent claudication is due to the relative ischaemia brought about by this compression (Blau \& Logue, I96I). It is certainly common in those patients with lumbar narrowing. In Verbiest's two papers (1954, 1955) twelve out of thirteen patients suffered from it; each of the two patients described by Brisk et al. (1964), Graveleau and Guiot (1964), Joffe et al. (1966) suffered from it. And, as might be expected, it also occurs in achondroplasiacs (Hancock and Phillips, 1965). Standing of itself may precipitate symptoms - this is in effect 'static claudication', when spinal extension narrows the canal to a critical degree.

Narrowing is diffuse throughout the whole of the achondroplasiac spine; it is tempting to conclude that congenital, but not diffuse, narrowing is a forme fruste of achondroplasia. The pedicles are shortened in both congenital narrowing and achondroplasia. In the latter the shortening is caused by premature fusion of pedicles to laminae (Donath \& Vogl, 1925). It is likely that a similar mechanism is responsible for congenital canal narrowing. In the lumbar region both thickened laminae and shortened pedicles may contribute to the narrowing; in the neck however, laminar thinning may occur (Hinck et al., I966, case R. F.; case E. D., this paper) so that pedicular shortening can be the only cause of bony narrowing of the canal in these instances.

Epstein et al. (1962) did not find the lumbar interpedicular distances reduced below normal in ten patients, though their measurements were within the lower limits of normal. Schlesinger and Taveras (1953), however, regard abnormal reduction of this space as an important feature; patient E. B. illustrated it clearly. It is probably a measure of the degree of severity of the condition. Achondroplasiacs also show a remarkable reduction of the inter-pedicular distance.

Timely laminectomy can be of value in both conditions. 


\section{SUMMARY}

Further examples of congenital narrowing of the spinal canal in the lumbar and cervical regions are presented. It is implied that the condition is a nosological entity. Neurogenic intermittent claudication often accompanies the lumbar variety; the diagnosis in the cervical region is, however, radiological. The similarity to some of the features of achondroplasia is stressed. Symptoms are usually relieved by an adequate laminectomy.

\section{RÉsumÉ}

Des exemples de rétrécissement du canal vertébral au niveau de la région lombaire et cervicale sont présentés. Il s'agit ici d'une entité nosologique. La claudication intermittente neurogène accompagne souvent la variété lombaire. Le diagnostic de ces rétrécissements au nivieau cervical est radiologique. L'auteur insiste sur la similarité avec l'achondroplasie. La laminectomie permet d'améliorer en général les symptômes.

\section{ZUSAMMENFASSUNG}

Beispiele von kongenitaler Verengung des Spinalkanals werden beschrieben. Dieses Krankheitsbild stellt eine Einheit für sich dar. Neurogenes intermittierendes Hinken ist ein häufiges Symptom der lumbalen Varietät, während die Diagnose in der zervikalen Region durch das Röntgenbild erfolgt. Die Ähnlichkeit zur Achondroplasie wird betont. Die Symptome werden im allgemeinen durch adequate Laminektomie besëitigt.

\section{ACKNOWLEDGMENTS}

I am grateful to Mr D. C. Provan for referring E. B., and Dr B. Phillips for referring D. E. W. Drs A. Jones and J. L. G. Thomson made the radiological measurements.

\section{REFERENCES}

Bailey, P. \& Casamajor, L. (I9i I). F. nerv. ment. Dis. 38, 588.

BlaU, J. N. \& Logue, V. (I96I). Lancet, I, I08I.

Brisk, A., Lerner, M. A. \& BrahaM, J. (I964). F. Neurosurg. 2 I, 207.

Cramer, F. (1933/4). Bull. neurol. Inst. N.Y. 3, $50 \mathrm{I}$.

Dejerine, J. (I9I I). Presse méd. 19, 98I.

Donath, J. \& Vogl, A. (1925). Wien Arch. inn. Med. I0, I.

EhNi, G. (1965), Tex. St. F. Med. 61, 746.

ElsBERG, C. A. \& DYke, C. G. (1934). Bull. neurol. Inst. N.Y. 3, 359.

Epstein, J. A. (1960). F. Neurosurg. I 7, 991 I.

Epstein, J. A., Epstein, B. S. \& Lavine, L. (I962). F. Neurol. Neurosurg. Psychiat. 25, I65

Evans, J. G. (1964). Bt. med. F. 2, 985.

vaN GELDEREN, C. (1948). Acta psychiat. scand. 23, 57.

Graveleau, J. \& Guiot, G. (I964). Presse méd. 72, 3344.

Hancock, D. O. \& Phillips, D. G. (1965). Int. F. Paraplegia, 3, 23.

Hinck, V. C., Hopkins, C. E. \& Savara, B. S. (I962). Radiology, 79, 97.

Hinck, V. C., Gordy, P. D. \& Storino, H. E. (I964). Neurology, Minneap. 14, 864.

HincK, V. C. \& SACHDEV., N. S. (I966). Brain, 89, 27.

Joffe, R., Appleby, A. \& Arjona, V. (1966). F. Neurol. Neurosurg. Psychiat. 29, 315.

Payne, E. E. \& SPillane, J. D. (I957). Brain, 80, 57 I.

Schlesinger, E. B. \& Taveras, J. M. (1953). Trans. Am. neurol. Ass. 263.

Teng, P. \& Papatheodorou, C. (1963). Br. F. Radiol. 36, I22.

Thomson, J. L. G. (1967). Personal Communication.

Verbiest, H. (1954). F. Bone ft. Surg. 36-B, 230.

Verbiest, H. (I955). F. Bone ft. Surg. 37-B, 576. 